\title{
Anaplastic Lymphoma Kinase (ALK) Translocation Re- arrangement Renal Cell Carcinomas: A Review and Update of the
}

\section{Literature}

Anthony Kodzo-Grey Venyo

North Manchester General Hospital, Department of Urology Manchester, M8 5RB. United Kingdom.

*Corresponding Author: Anthony Kodzo-Grey Venyo, North Manchester General Hospital, Department of Urology Manchester, M8 5RB. United Kingdom.

Received date: September 07, 2020; Accepted date: September 25, 2020; Published date: October 19, 2020

Citation: Anthony K-G Venyo. (2020) Anaplastic Lymphoma Kinase (ALK) Translocation Re-arrangement Renal Cell Carcinomas: A Review and Update of the Literature. International Journal of Clinical Case Reports and Reviews. 3(5); DOI: 10.31579/2690-4861/055

Copyright: () 2020 Anthony Kodzo-Grey Venyo, This is an open-access article distributed under the terms of the Creative Commons Attribution License, which permits unrestricted use, distribution, and reproduction in any medium, provided the original author and source are credited.

\begin{abstract}
Less than 50 cases of anaplastic lymphoma kinase (ALK) re-arrangement-associated renal cell carcinoma (ALK-RCC) been reported in the literature. ALK-RCC does affect children who have sickle cell trait and also adults with no evidence of sickle cell trait or sickle cell disease. ALK-RCC may be diagnosed incidentally or in individuals who have typical symptoms that simulate those or more common renal tumours. Diagnosis of ALK-RCC does depend upon histopathology examination, immunohistochemistry studies as well as electron microscopy studies of nephrectomy / biopsy specimens of the kidney lesion that that show: typical pathology examination features of ALK-RCC as described within the text. Immunohistochemistry studies in ALK-RCC tend to show positive staining for: ALK, PAX8, INI1 (Intact), AE1/AE3, CAM5.2, CK7, EMA, LMWCK, P53, +Vimentin, CD10 (this tends to be variable), AMACR (this tends to be variable), and TFE3 (within the majority of the tumour cells). Majority of ALK-RCCs have been localized tumours at the time of initial diagnosis, but some cases of locally advanced tumours or tumours associated with metastases have been reported. There is no consensus opinion on the treatment of ALK-RCC but nephrectomy has been undertaken in most cases with good short term and medium term; nevertheless metastases and death have been reported. Response to utilization of to ALK inhibitor alectinib, as well as ALK Translocation Renal Cell Carcinoma does respond to Crizotinib. Improvements in the outcome of ALK-RCC could possibly be achieved through routine screening of sickle cell trait individuals, routine pre-operative per-cutaneous radiology imaging guided biopsies of all renal lesions, small localized tumours could be treated by (a) partial nephrectomy, or (b) radical nephrectomy, (c) cryotherapy, (d) radiofrequency ablation, (e ) irreversible electroporation plus / minus adjuvant therapy (radiotherapy, chemotherapy or ALK inhibitor plus or minus immunotherapy.
\end{abstract}

Key Words: anaplastic lymphoma kinase-associated renal cell carcinoma; histopathology; electron microscopy; cytogenetics, nephrectomy; alk-inhibitor. ALK; PAX8; INI1; AE1/AE3; CAM5.2; CK7; EMA; LMWCK; P53; Vimentin; CD10; AMACR; TFE3.

\section{Introduction}

Anaplastic lymphoma kinase (ALK) is stated to be a membraneassociated receptor kinase which belongs to insulin superfamily [1]. It has been iterated that ALK re-arrangement is oncogenic which does activate cellular signalling pathways by dimerization through the specific structures of fusion partners [2]. It has been stated that genetic alterations within ALK has been found in various tumours [3]. The World Health Organization (WHO) 2016 edition assigned anaplastic lymphoma kinase (ALK) re-arrangement-associated renal cell carcinoma (ALK-RCC) as an emerging kidney tumour entity [3]. It has been iterated that the identification of ALK-RCC is important or pertinent in that ALK inhibitors have been demonstrated to be effective with regard to treatment of ALK re-arrangement renal cell carcinoma. [3]. It had been iterated that up to March 2020, 28 cases of ALK-RCC had been reported and six partner genes had been confirmed within the tumour [3], [4] [5] [6] [7]. It has been iterated that the recognition of ALK alterations within neoplasms is important in view of the potential benefit of ALK inhibitors. Despite this knowledge, it had been noted that screening for ALK re-arrangement within RCC has not been routinely undertaken in view of costeffectiveness problems. [3] [8]. It has been indicated that previous studies had reported that ALK-RCC is encountered in less than $1 \%$ of renal cell carcinomas (RCCs) and in 3.8\% of paediatric and young adults who have renal cell carcinomas (RCCs) [3] [9] [10]. It has been stated that attempts had been undertaken to ascertain the the characteristics of ALK-RCC; nevertheless, in view of its rarity, as well as the various histological features of the tumour depending upon the fusion partners does make it difficult. [3]. Many partner genes including VCL, TPM3, EML4, HOOK1, STRN, and RAD51AP2 have been reported in association with ALK-RCC in association with their linkages with a variety of clinicopathological findings. [3] It has been documented that out of the aforementioned genes, VCL-ALK Renal cell carcinoma had been described in children who have sickle cell trait as well as that TPM3 had been primarily reported as a partner in ALK-RCC [3]. It has also been stated that the coiled-coil structure of TPM3 does induce dimerization of 
the fusion protein protein and does promote ALK activation. Considering that less than 30 cases of ALK Translocation-associated renal cell carcinomas have been reported so far, it would not be surprising if majority of clinicians globally are not aware of the diagnostic features, clinical behaviour, management as well as outcome of the malignancy because most people globally would certainly have not encountered the tumour before. The ensuing review and update of the literature on ALK Translocation-associated Renal Cell Carcinoma is divided into two parts: (A) Overview, and (B) Miscellaneous narrations and discussions from some case reports, case series, and studies related to ALK TranslocationAssociated Renal Cell Carcinoma.

\section{Aim}

To review and update the literature on ALK Translocation-Associated Renal Cell Carcinoma.

\section{Method}

Internet data bases were searched including: Google, Google Scholar, Yahoo, and PUBMED. The search words that were used included: ALK Translocation-Associated Renal Cell Carcinoma, ALK Renal Cell Carcinoma, and ALK RCC. Thirty four references were identified which were used to write the review and update of the literature on ALK Translocation-Associated Renal Cell carcinoma that is divided into two parts: (A) Overview and (B) Miscellaneous narrations and discussions from some case reports, case series, and studies related to ALK Translocation-Associated Renal Cell Carcinoma.

Result / Review and Update of the Literature on ALK Translocation-Associated Renal Cell Carcinoma.

\section{(A) Overview}

\section{Definition / General Comments}

- It has been iterated that ALK Translocation Renal Cell Carcinoma is a terminology that is utilized for renal cell carcinoma (RCC) that is associated with anaplastic lymphoma kinase (ALK) gene re-arrangement (chromosome 2p23). [11]

- It has been documented that ALK Translocation Renal Cell Carcinoma does tend to affect children who have sickle cell trait as well as adults who do not have sickle cell trait. [11]

- It has been stated that ALK Translocation Renal Cell Carcinoma that affects children does simulate renal medullary carcinoma in that it tends to be medulla centric and it tends to be associated with diffuse infiltrating growth that contains lymphoplasmacytic infiltrate as well as large polygonal discohesive or spindle cells and cytoplasmic vacuoles as well as vesicular nuclei [11].

- It has been iterated that ALK Translocation Renal Cell Carcinoma that affects adults does tend to exhibit heterogeneous solid architecture as well as microscopic examination of the specimen does demonstrate mucinous cribriform, signet-ring, as well as solid rhabdoid patterns, and high-grade eosinophilic cells and intra-cytoplasmic lumens [11] [12] [13].

Essential Features

- It has been documented that microscopy pathology examination features of ALK Translocation Renal Cell Carcinoma does demonstrate an architecturally heterogeneous eosinophilic tumour that contains polygonal, rhabdoid, signet ring and spindled cells, which produce mucin and does also contain cytoplasmic vacuoles [11].

- It has also been iterated that immunohistochemistry staining studies of ALK Translocation Renal Cell Carcinoma does demonstrate Diffusely positive ALK protein expression (positive staining for ALK protein) [11].

- It has also been stated that in cases of ALK Translocation Renal Cell Carcinoma, ALK gene re-arrangements tend to be demonstrated by utilization of FISH, RT-PCR, or RNA sequencing [11].

Terminology

- It has been iterated that the first documented case of VCL-ALK fusion renal cell carcinoma was described in 2010 [11] [14].

- It has been stated that the three terminologies that are utilized for ALK Translocation Renal Cell Carcinoma include: [11]

\section{- ALK re-arrangement associated RCC. \\ - ALK translocation RCC \\ - ALK-RCC}

- It has been documented that ALK Translocation Renal Cell Carcinoma is a provisional tumour entity that has been incorporated into the 2016 World Health Organization (WHO) Classification of Tumours [11].

Epidemiology

- It has been iterated that ALK Translocation Renal Cell Carcinoma is an uncommon tumour and less than 25 cases of the tumour have been reported [11].

- It has been documented that cases of ALK Translocation Renal Cell Carcinoma have tended to have a bimodal distribution with regards to age as follows:

- ALK Translocation Renal Cell Carcinomas do affect children who have Sickle Cell Trait, and the disease tends to affect children of African descent whose ages have tended to range between 6 years and 19 years.

- ALK Translocation Renal Cell Carcinomas do also affect adults who do not have Sickle Cell Trait and their ages have tended to range between 33 years and 61 years.

- It has been iterated that with regard to the incidence of ALK Translocation Renal Cell Carcinoma, the incidence in children has ranged between $3.5 \%$ and $3.8 \%$ of all renal carcinomas and the incidence in adults, has ranged between $0.4 \%$ to $0.5 \%$ of all renal cell cancers in adults [9] [10] [11] [13] [15].

Sites

It has been documented that with regard to the sites of the kidney that tend to be affected by ALK Transformation Renal Cell Carcinoma, the ensuing summations can be made: [11]

- $\quad$ ALK Translocation Renal Cell Carcinomas tend be encountered as solitary kidney tumours.

- $\quad$ ALK Translocation Renal Cell Carcinomas tend to often affect the medulla of the kidney, the renal pelvis, as well as the middle of the kidney.

Pathophysiology of ALK Translocation Renal Cell Carcinoma

The ensuing remarks have been made regarding the pathophysiology of ALK Translocation Renal Cell Carcinoma: [11]

- ALK does belong to the insulin receptor tyrosine kinase superfamily and it tends to be normally expressed at a low-level within the central nervous system. [11]

- $\quad$ ALK translocation does represent an oncogenic driver mutation which perhaps does occur during the early stage of carcinogenesis [13]. 
Aetiology

- With regard to the aetiology of ALK Translocation Renal Cell Carcinoma in children, the Sickle trait has been noted to be a factor in a sub-set of the patients [8] [11].

Clinical features

- It has been documented that pertinent clinical features of ALK Translocation Renal Cell Carcinoma include haematuria, flank pain, abdominal pain, or peri-umbilical pain [10] [11] [12].

- It has been documented that 33 percent of cases of ALK Translocation Renal Cell Carcinoma have been diagnosed incidentally [11].

- It has been stated that ALK Translocation Renal Cell Carcinomas have tended to be pT1a or pT1b tumours. [11].

Laboratory Investigations

Urine

- Urinalysis, urine microscopy and culture are routine tests that tend to be undertaken in the initial assessment and follow-up of all individuals who have ALK Translocation-Associated RCC and most often the results tend to be normal but there could be red blood cells in the urine specimens of those individuals who have been having haematuria. In the event of evidence of urinary tract infection, it would be treated with an appropriate antibiotics based upon the antibiotic sensitivity pattern of the cultured organism and the allergic status of the individual.

Haematology blood tests

- Full blood count, erythrocyte sedimentation rate, and coagulation screen are routine tests that tend to be undertaken in the initial and follow-up assessments of individuals who have ALK Translocation-Associated Renal Cell Carcinoma and most often the results would be normal but in cases of recurrent haematuria there may be evidence of anaemia. If there is any abnormality, it would be investigated and treated to improve upon the general condition of the individual.

- Usually individuals who have sickle cell trait tend to have haemoglobin electrophoresis prior to their presentation and the results would be available.

Biochemistry blood tests

- Serum urea, glomerular filtration rate, electrolytes, blood glucose and liver function tests are routine tests that tend to be undertaken in the initial and follow-up assessments of individuals who have ALK Translocation-Associated Renal Cell Carcinoma and most often the results tend to be normal but if there is any abnormality it would be investigated and treated accordingly to improve the general condition of the individual.

Radiology imaging features

Ultrasound scan

- It has been stated that ultrasound scan of abdomen, pelvis, and renal tract does show a hypo-echoic medulla centric mass. [11]

- Ultrasound scan is a common radiology imaging that tends to be undertaken in the initial assessments of individuals who have ALK Translocation-Associated Renal Cell Carcinoma and ultrasound scan of renal tract, abdomen, and pelvis can be undertaken in the follow-up assessments of individuals who have undergone nephrectomy or partial nephrectomy for the malignancy in addition to chest x-ray to establish presence or absence of metastasis but this has been superseded by utilization of CT Scan/MRI scan of thorax abdomen and pelvis.
- Ultrasound scan-guided biopsy of the kidney lesion can be done pre-operatively for pathology examination to establish the diagnosis following which various treatment options could be discussed including: Partial nephrectomy, radical nephrectomy, cryotherapy, radiofrequency ablation, and irreversible electroporation plus adjuvant therapy including chemotherapy, radiotherapy, ALK inhibitor, and immunotherapy.

Computed tomography scan

- It has been documented that simple computed tomography scan of abdomen and pelvis does show an iso-dense kidney mass [11].

- Computed Tomography Scan of abdomen and pelvis does show a slightly enhanced or heterogeneously enhancing mass [12].

- CT scan is a common radiology imaging that tends to be undertaken in the initial assessments of individuals who have ALK Translocation-Associated Renal Cell Carcinoma and CT scan of thorax, renal tract, abdomen, and pelvis can be undertaken in the follow-up assessments of individuals who have undergone nephrectomy or partial nephrectomy for the malignancy in addition to chest $\mathrm{x}$-ray to establish presence or absence of metastasis.

- $\quad$ CT scan-guided biopsy of the kidney lesion can be done preoperatively for pathology examination to establish the diagnosis following which various treatment options could be discussed including: Partial nephrectomy, radical nephrectomy, cryotherapy, radiofrequency ablation, and irreversible electroporation plus adjuvant therapy including chemotherapy, radiotherapy, ALK inhibitor, and immunotherapy.

Magnetic Resonance Imaging Scan

- MRI scan is a common radiology imaging that tends to be undertaken in the initial assessments of individuals who have ALK Translocation-Associated Renal Cell Carcinoma and MRI scan of thorax, renal tract, abdomen, and pelvis can be undertaken in the follow-up assessments of individuals who have undergone nephrectomy or partial nephrectomy for the malignancy in addition to chest x-ray to establish presence or absence of metastasis.

- $\quad$ MRI scan-guided biopsy of the kidney lesion can be done preoperatively for pathology examination to establish the diagnosis following which various treatment options could be discussed including: Partial nephrectomy, radical nephrectomy, cryotherapy, radiofrequency ablation, and irreversible electroporation plus adjuvant therapy including chemotherapy, radiotherapy, ALK inhibitor, and immunotherapy.

Positron Emission Tomography - Computed Tomography Scan

- PET-CT scan tends to be undertaken in the follow-up assessments of individuals who have undergone treatment for ALK Translocation-Associated Renal Cell Carcinoma to establish if they have developed metastasis as well as the site of the metastasis.

Isotope Bone Scan

- Isotope bone scan tends to be undertaken in the follow-up of individuals who have had treatment for ALK TranslocationAssociated Renal Cell Carcinoma to establish if they have developed bone metastasis.

Prognostic factors

- It has been iterated that with regard to the prognosis of Children who had VCL-ALK, so far following treatment, no case of local recurrence or distant metastasis has been reported [11]. 
- It has been stated that with regard to adult non-VCL-ALK Renal Cell Carcinomas, 33 percent of the tumours tend to be associated with adverse prognosis. [10] [11] [13]

- It has been iterated that in view of the few reported cases and the short period of follow-up reported in association with the reported cases, the accurate assessment of the prognosis and the associated risk factors cannot be ascertained at the moment [11].

Treatment

Some of the treatment strategies that have been utilized for ALK Translocation Renal Cell Carcinoma have been summated as follows: [11]

- $\quad$ Primary Localized Tumour - Cases of early stage localized ALK Translocation Renal cell carcinoma have been treated by means of nephrectomy or nephroureterectomy.

- $\quad$ Metastatic ALK Translocation Renal Cell Carcinomas - It has been documented that ALK-RCC does respond to ALK inhibitor alectinib [11] [16].

- It has also been stated that ALK Translocation Renal Cell Carcinoma does respond to Crizotinib like the response of rearrangement lung cancer for this treatment [17].

Macroscopic examination features

The macroscopy pathology examination features of ALK-Translocation Renal Cell Carcinoma have been summated as follows: [11]

- Paediatric patients who have ALK Translocation Renal Cell Carcinoma - It has been iterated that macroscopic examination of the kidney tumour of a paediatric individuals who has ALK Translocation Renal Cell Carcinoma does tend to demonstrate a solid tumour mass that is irregular with regard to shape as well as associated with infiltrative borders [12] [18].

- Adult Individuals who have ALK Translocation Renal Cell Carcinoma - It has been iterated that macroscopic pathology examination of the kidney tumours of an adult individual who has ALK Translocation Renal Cell Carcinoma does tend to show a well-demarcated tumour that is localized within the middle of the kidney and which tends to be tan to brown, or white to grey with regard to colour in which cystic change or haemorrhage could found; however, there tends to be absence of a pseudo-capsule encompassing the tumour. [11]

- With regard to the size of the tumour, it has been stated that gross examination of ALK Translocation Renal Cell Carcinoma does tend to reveal a kidney tumour that measures between 3 $\mathrm{cm}$ and $7 \mathrm{~cm}$. [11]

Microscopy histopathology examination features.

The microscopy histopathology examination features of ALK Translocation Renal Cell Carcinomas in Children and Adults have been summated as follows: [11]

- Paediatric Individuals who have ALK Transformation Renal Cell Carcinoma - of Microscopy pathology examination of a paediatric individuals who has ALK Translocation Renal cell carcinoma would tend to show: [9] [18].

- Diffuse infiltrating growth pattern that is sheet like.

- Evidence of lymphoplasmacytic infiltrate as well as intra-vascular sickling.

- Round, oval and polygonal tumour cells that contain abundant vaguely granular eosinophilic cytoplasm, as well as frequent intra-cytoplasmic lumens.
○ Presence of abundant mucin within the background as well as intra-cytoplasmic mucin.

- Presence of moderately polymorphic, and predominantly vesicular nuclei, that contain small nucleoli, and occasional grooves, as well as rare vacuoles.

- $\quad$ Adult Individuals who have ALK Transformation Renal Cell Carcinoma - of Microscopy pathology examination of an adult individuals who has ALK Translocation Renal cell carcinoma would tend to show: [13] [17].

- Evidence of more heterogeneous architecture with demonstration of solid, mucinous cribriform, reticular, tubular, papillary growth, dis-cohesive sheets or infiltrating single cells.

- Presence of eosinophilic polygonal cells, rhabdoid or signet ring as a result of intracytoplasmic vacuolization.

○ The tumour could contain Psammoma bodies as well as foamy macrophages.

Immunohistochemistry staining studies

Positive staining

- It has been iterated that immunohistochemistry staining studies of ALK Translocation Renal Cell Carcinoma specimens tend to show tumour cells that exhibit positive staining for the following tumour markers: [11]

$\begin{array}{ll}\circ & \text { ALK } \\ \circ & \text { PAX8 } \\ \circ & \text { INI1 (Intact) } \\ \circ & \text { AE1/AE3 } \\ \circ & \text { CAM5.2 } \\ \circ & \text { CK7 } \\ \circ & \text { EMA } \\ \circ & \text { LMWCK } \\ \circ & \text { P53 } \\ \circ & \text { Vimentin } \\ \circ & \text { CD10 (this tends to be variable) } \\ \circ & \text { AMACR (this tends to be variable) }\end{array}$

- It has also been iterated that immunohistochemistry staining studies of ALK Translocation Renal Cell Carcinoma specimens tend to show tumour cells that exhibit positive staining for the following tumour marker: [11]

- TFE3 (within the majority of the tumour cells) [12] [14] [17].

Negative staining

- It has been iterated that immunohistochemistry staining studies of ALK Translocation Renal Cell Carcinoma specimens tend to show tumour cells that exhibit negative staining for the following tumour markers: [11]

$\begin{array}{cl}\circ & \text { RCC } \\ \circ & \text { CD117/KIT } \\ \circ & \text { S100 } \\ \circ & \text { HMB45 } \\ \circ & \text { Melan A } \\ \circ & \text { Cathepsin K } \\ \circ & \text { WT1 }\end{array}$


- It has also been iterated that immunohistochemistry staining studies of ALK Translocation Renal Cell Carcinoma specimens tend to show tumour cells that exhibit negative staining for the following tumour marker: [11]

- $\quad \mathrm{Ki} 67-$ In this case it has been stated that the Ki67 has tended to be very low and this has tended to be less than $5 \%$.

Electron Microscopy Examination Features

- It has been iterated that electron microscopy examination of ALK Translocation Renal Cell Carcinoma does show tumour cells that contain bundles of tonofilaments, intercellular junctions, desmosomes, intra-cytoplasmic lumens that are lined by microvilli as well as lipofuscin-like lysosomal structures [11] [18].

Molecular and cytogenetics examination features

- It has been iterated that electron microscopy and cytogenetics studies of ALK Translocation Renal Cell Carcinoma specimens tend to show the following features: [11].

○ VCL-ALK fusion which has tended to be strongly associated with sickle cell trait [19].

- TPM3-ALK fusion which has tended not to be associated with sickle cell trait [18].

- Other less common fusions that include: STRNALK, EML4-ALK, and HOOK1-ALK [12] [20].

- Clonal inversion that involve 2p23 [14]

- No fusion but increased copy number of ALK1there may be no evidence of fusion but an increased number of ALK1 may be found [[21].

- It has also been pointed out that it is worth noting that ALK copy number gain could be found in up to $10 \%$ of clear cell renal cell carcinoma and this also tends to be associated with worse cancer specific survival [11] [22].

\section{Differential diagnosis}

It has been pointed out that with regard to differentiating ALK Translocation Renal Cell Carcinoma, broadly speaking, immunohistochemistry staining studies with utilization of ALK antibody as well as molecular studies that confirm ALK Translocation are critical for the diagnosis of ALK Translocation Renal Cell Carcinoma [11]. Some of the differential diagnoses of ALK Translocation Renal Cell Carcinoma include:

- Renal medullary carcinoma - [11]

- It has been stated that renal medullary carcinoma also does tend to affect young patients who have sickle cell trait and that the tumour tends to be a very large aggressive tumour and which also tends to be associated with metastasis at the time of the initial presentation of the lesion.

- It has been stated that in cases of Renal medullary carcinoma, there tends to be loss of INI1 and the KI67 proliferation rate tends to be high [11].

- $\quad$ Collecting duct carcinoma -

- It has been pointed out that collecting duct carcinoma of the kidney also does affect the medullary area of the of the kidney but the tumour tends to be larger with regard to its size, and the tumour tends to be a predominantly tubular growth, with evidence of stromal desmoplasia as well as the Ki67 proliferation rate of the tumour tends to be high [11].

- MiT Family Translocation Renal Cell Carcinoma -

- It has been iterated that MiT Translocation Renal Cell Carcinoma could have morphology that is similar to the morphology of ALK Translocation Renal Cell Carcinoma but MiT Translocation Renal Cell Carcinoma does tend to be TFE3 positive [11].

- It has been stated that MiT Translocation Renal Cell Carcinoma can exhibit positive immunohistochemistry staining for melanocyte markers and for cathepsin $\mathrm{K}$.

- Papillary Renal Cell Carcinoma and mucinous tubular and spindle cell carcinoma -: [11]

- It has been iterated that the aforementioned tumour (s), also tend to contain tubule-papillary architecture, and also tend to produce mucin, tend to contain Psammoma bodies, tend to contain macrophages as well as overlapping immuneprofile.

- The aforementioned tend to exhibit absence of ALK expression with negative staining for ALK.

- Unclassified Renal Cell Carcinoma [11]

- It has been pointed out that unclassified renal cell carcinoma tends to exhibit negative immunohistochemistry staining for ALK [11].

- Metastases

- It has been stated that metastases to the kidney from a primary malignant tumour elsewhere especially ALK re-arranged adenocarcinoma of the lung is one of the differential diagnoses of ALK Translocation Renal Cell Carcinoma [11].

- It has been stated that with regard to metastases within the kidney from a primary tumour elsewhere, immunohistochemistry staining studies tend to exhibit positive staining for TTF1/Napsin A as well as negative staining for PAX8.

- It has also been advised that in order to diagnose metastasis to the kidney, it is important to check the clinical history of the patient. [11] [12] [17]

(B) Miscellaneous narrations and discussions from some case reports, case series, and studies related to ALK Translocation Renal Cell Carcinoma.

Woo et al. [3] reported a 14-year-old male who had manifested with visible haematuria. He had computed tomography (CT) scan of abdomen and pelvis and renal tract which showed a $5.3 \mathrm{~cm} \mathrm{x} 4.5 \mathrm{~cm}$ that was welldemarcated, solid/cystic mass within the upper pole of his left kidney (see figure $1 \mathrm{~A})$. He was asymptomatic otherwise. The results of his routine haematology and biochemistry blood tests were within normal range. $\mathrm{He}$ had haemoglobin electrophoresis which showed normal red blood cells. He underwent left radical nephrectomy for a stage III (pT1bN1) tumour and he did not receive any adjuvant therapy pursuant to that. During his 4 months post-operative follow-up, there was no evidence of local recurrence or metastasis. 

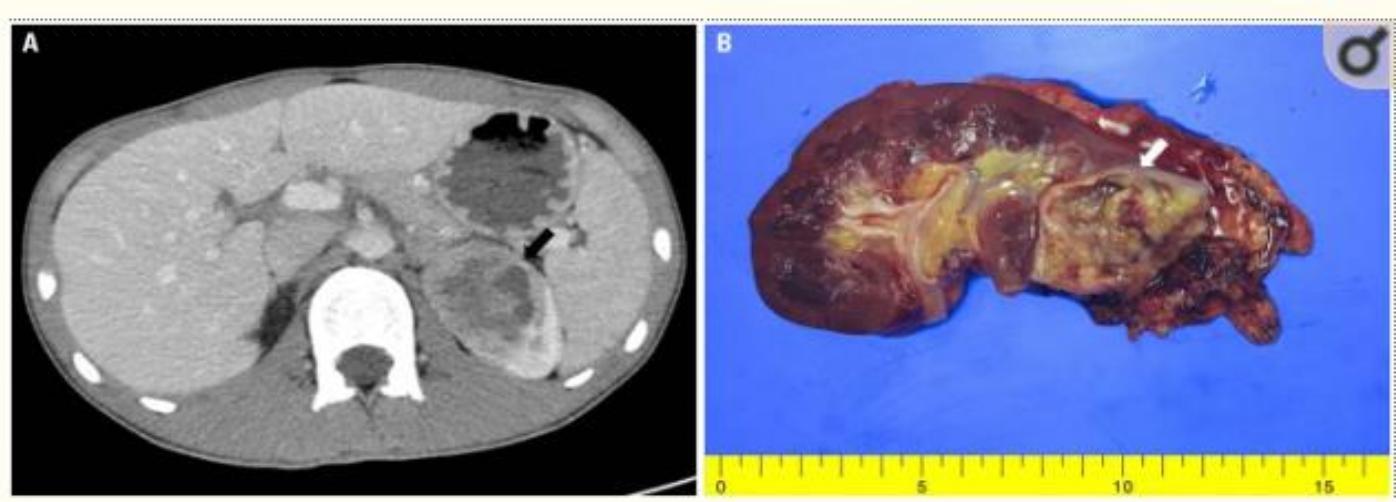

Figure 1.

Gross findings of ALK rearrangement-associated renal cell carcinoma. (A) A well-demarcated, solid cystic mass (arrow), at the upper pole of the left kidney is observed on abdominal computed tomography. (B) The mass is yellow-to-grey, involving the renal medulla and cortex. [3] which permits unrestricted non-commercial use, distribution and reproduction in any medium, provided the original work is properly cited.

Macroscopic pathology examination of the specimen showed that the tumour mass had involved the medulla and cortex of the left kidney (see figure I B). Microscopy pathology examination of the tumour demonstrated a diffuse growth, focal tubolo-cystic changes, and multifocal inflammatory cell infiltration that simulated medullary renal carcinoma (RMC) (see figure $2 \mathrm{~A}$ and figure $2 \mathrm{~B}$ ). The infiltrated inflammatory cells comprised mainly of lymphocytes. The tumour cells were noted to be dis-cohesive as well as epithelioid and contained abundant eosinophilic cytoplasm as well as cytoplasmic vacuoles. Even though majority of the nuclei were round to oval, some of the nuclei were noted to be multi-nucleated as well as pleomorphic consistent with ISUP grading of 4. Mitosis was visualized in two to three of the cells per 10 high-power fields with a Ki-67 proliferation index of $10 \%$. There was abundance of mucin within the background as well as intracytoplasmic mucin was visualized. There was evidence of coagulative necrosis within the tumour. Immunohistochemistry staining studies of the tumour showed that the tumour cells had exhibited diffuse positive staining for pancytokeratin as well as preservation of INI1 expression. The tumour cells additionally exhibited positive staining for PAX8, CD10, as well as for Vimentin. Immunoreactivity for TFE3, but without TFE3 re-arrangement was found. Next generation sequencing studies of the tumour demonstrated a TPM3-ALK fusion gene between exon 7 of TPM3 and exon 20 of ALK. The tumour demonstrated membraneous as well as cytoplasmic ALK-expression within the tumour cells (see figure $2 \mathrm{C}$ ). Woo et al. [3] stated the following:

- With the incusion of their reported case, 8 cases of TPM3-ALK Renal cell carcinomas had been reported in the literature.

- $\quad$ TPM3-ALK RCCs had been reported in five (5) teenagers and three (3) young to middle age adults.

- Men and women had been affected by TPM3-ALK RCC equally; nevertheless, the number of patients who had so far been reported as having TPM3-ALK had been too small to seek any meaning into the sex distribution of the tumour.

- $\quad$ None of the patients that had been reported as having TPM3ALK RCC had sickle cell trait.

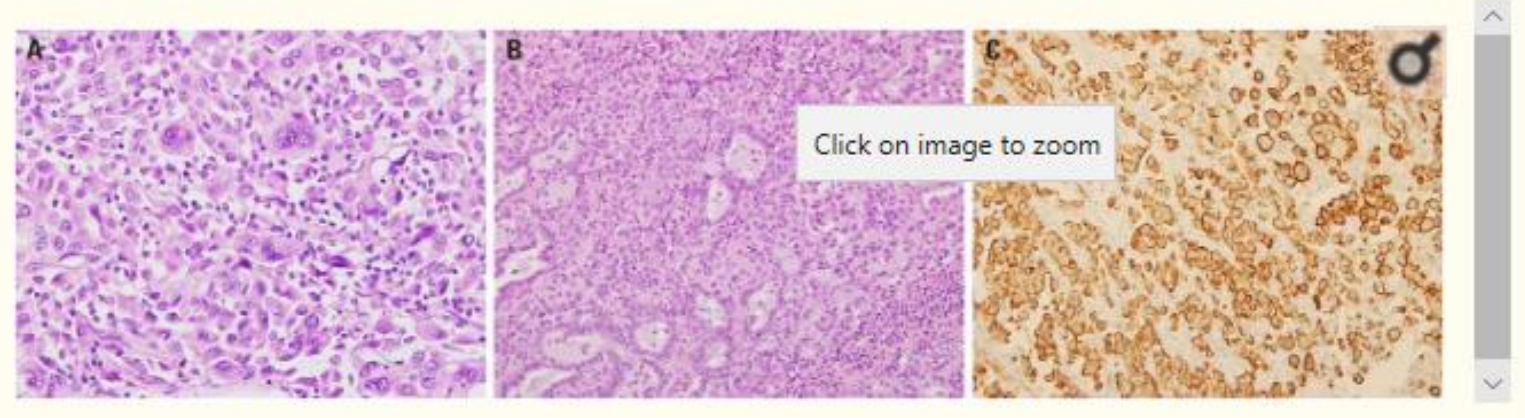

\section{Figure 2.}

Microscopic findings of ALK rearrangement-associated renal cell carcinoma. (A) The tumour cells are dis-cohesive and epithelioid with abundant eosinophilic cytoplasm, cytoplasmic vacuoles, and intracytoplasmic mucin. Some tumour cells have extreme nuclear pleomorphism and multinucleated giant cells (H\&E, x400). (B) The tumour shows diffuse growth and focal tubulo-cystic changes (H\&E, $\mathrm{x} 200$ ). (C) Membranous and cytoplasmic ALK expression was confirmed by immunohistochemistry (x200). [3] which permits unrestricted noncommercial use, distribution and reproduction in any medium, provided the original work is properly cited. [23] screened consecutively resected renal cell carcinomas (RCCs) from one institution for the expression of ALK with utilization of immunohistochemistry staining studies which was ensued by the undertaking of fluorescence in situ hybridization to in order to confirm the ALK gene alteration in ALK immunohistochemistry staining positive cases of renal cell carcinoma. Lee et al. [23] screened 829 RCCs by undertaking immunohistochemistry staining studies on the specimens of the tumours and they undertook fluorescence in situ hybridization analysis with utilization of ALK dual-colour break-apart re- 
arrangement probe. Histopathology review analysis and additional immunohistochemistry analyses were undertaken with regard to the positive cases. With regard to the results, Lee et al. [23] reported that they did find 1 ALK positive case and the initial histopathology examination diagnosis of the tumour was papillary renal cell carcinoma type 2 . The finding of 1 ALK positive RCC out of 829 cases constituted $0.12 \%$ the RCC cases and there were 53 cases of papillary renal cell carcinoma which meant that one case of the 53 cases constituted $1.9 \%$ of papillary renal cell carcinomas being positive for ALK. The patient was a 44-yearold man whose renal cell carcinoma was diagnosed incidentally based upon routine medical check-up assessment. He was alive and well 12 years pursuant to his operation without any evidence of local recurrence or metastasis. Pathology examination of the tumour demonstrated a papillary and tubular pattern and immunohistochemistry staining of the tumour showed tumour cells that exhibited focal positive staining for CD10, and positive staining for: epithelial membrane antigen (EMA), cytokeratin 7, pan-cytokeratin, PAX-2, as well as for vimentin. Lee et al. [23] made the ensuing conclusions:

- They had found the first case of RCC that was associated with ALK gene re-arrangement in Korean patients by utilization of ALK immunohistochemistry staining studies among 829 patients who had renal cell carcinomas.

- The tumour demonstrated similar histopathology examination features and immunohistochemistry staining features that were similar to the features that were found in previously reported adult cases of renal cell carcinoma that were associated with ALK re-arrangement, and the tumour portended a relatively good prognosis.

It would be stated that the findings of this study has demonstrated additional pathology features of renal cell carcinomas. Nevertheless, some people would argue that the finding of 1 case out of 829 RCCs that amounted to $0.12 \%$ of cases being ALK re-arrangement RCCs which was associated with a good prognosis following routine radical nephrectomy and no adjuvant treatment would not be cost-effective and if similar findings are made then clinicians in the less resourced developing countries would consider the option of not undertaking routine ALKassessments of their RCCs in that it would appear to be more beneficial to utilize the resources for the study on the investigation of other malignancies of the results of the studies would provide information related to an alternative / additional treatment that would be aimed at improving the prognosis of patients.

Chen et al. [24] screened for ALK expression in 87 cases of pathology examination based diagnosed clear cell renal cell carcinomas (ccRCCs) by undertaking immunohistochemistry staining studies. Chen et al. [24] stated that four patients had tested positive for ALK expression based upon the immunohistochemistry studies and out of them they had confirmed the ALK expression by utilization of fluorescence in situ hybridization (FISH) test. Additionally, Chen et al. [24] did detect the existence of the echinoderm micro-tubule-associated protein-like 4/anaplastic lymphoma kinase (EML4-ALK) (E13:A20, variant 1) fusion gene in tumours from the two patients also with utilization of rapid amplification of cDNA ends (RACE)-coupled PCR sequencing and RTPCR. Chen et al. [24] also pointed out that they had first shown that enforced EML4-ALK expression could significantly promote in vitro proliferation, clonogenic colony formation and apoptosis resistance in HK2 immortalized normal tubular epithelial cells as well as their in vivo outgrowth when injected into immunocompromised nude mice. Chen et al. [24] reported their additional important finding that demonstrated that this pro-tumorigenic effect had been completely abolished by utilization of ALK-specific inhibitor crizotinib, which had indicated the potential effectiveness of ALK-specific inhibitors with regard to the treatment of ALK-re-arranged clear cell renal carcinoma (ccRCC) patients. They concluded that their data had revealed that ALK fusions do exist in adult clear cell renal cell carcinoma (ccRCC) and this finding would provide a rationale for the utilization of ALK inhibitor therapy in the management of selected patients who have clear cell renal cell carcinoma (ccRCC). It would be argued that this finding is significant in that if the results are reproduced in human beings, then this would provide concrete evidence that routine screening for ALK expression in all RCCs would prove useful with regard to the identification of patients who undergo treatment for ccRCC who would benefit from utilization of ALK inhibitors as adjuvant treatment for curative intent purposes.

Kuroda et al. [25] described 12 ALK-RCCs from 8 establishments together with their detailed clinical, pathological, immunohistochemical (IHC), fluorescence in situ hybridization (FISH), as well as nextgeneration sequencing (NGS) analyses. Kuroda et al. [25] reported that the ages of the patients had ranged between 25 years and 68 years and their mean was 46.3 years. Seven of the patients were females and five of the patients were males which demonstrated a female to male ratio of $1.4: 1$. The sizes of the tumours had ranged between $1.7 \mathrm{~cm}$ to $7.0 \mathrm{~cm}$ and the mean and median sizes of the tumours were $3.15 \mathrm{~cm}$ and $2.5 \mathrm{~cm}$ respectively. The pathology TNM staging of the tumours were documented as pT1a in 7 cases, pT1b in 1 patient, and pTN3a in 4 patients respectively. Follow-up information was available for 9 patients out of the 12 patients for which the follow-up had ranged between 2 months and 153 months and the mean follow-up was 37.6 months. Eight (8) of the patients were alive with no evidence of local recurrence or metastasis but one (1) patient was alive with distant metastases. Based upon the pathology examination features of the tumours, the tumours were stated to have demonstrated heterogeneous and difficulty to classify in 10 out of the 12 cases which typically had shown diverse architectural as well as cellular morphologies which had included: papillary, tubular, tubulocystic, solid, sarcomatoid (spindle cell), rhabdoid, signet-ring cell, and intracytoplasmic vacuoles, which were often set within a mucinous background. With regard to the remaining two tumours, one of them had morphology that simulated mucinous tubular and spindle cell renal cell carcinoma (MTSC-RCC-like), and the remaining tumour had features indistinguishable from metanephric adenoma. One additional case was also reported to have demonstrated a focal metanephric adenoma-like area, within an otherwise heterogeneous tumour. Immunohistochemistry staining studies of the tumours revealed that all the tumours had exhibited diffusely positive staining for ALK and PAX8. With regard to both cases that had metanephric adenoma-like features, WT1 and ALK were coexpressed in their immunohistochemistry studies. FISH tests were utilized that demonstrated ALK re-arrangement in 9 out of 11 tumours. ALK fusion partners were also identified in 12 cases with utilization of NGS, that included the previously reported cases of: STRN in 3 cases, TPM3 in 3 cases, EML4 in 4 cases, and PLEKHA7 in 1 case, as well as three novel fusion partners that included: CLIP1 in 1 case, KIF5B in 1 case, and KIAA127 in 1 case. Kuroda et al. [25] made the ensuing iterations:

- ALK-RCC does represent a genetically distinct entity that demonstrates a heterogeneous histopathological morphology features which had been expanded in their studies to include unreported metanephric adenoma-like and MTSC RCC-like variants.

- $\quad$ They would advocate a routine ALK immunohistochemistry staining studies screening for "unclassifiable RCC" that depict heterogeneous features.

Yang et al. [26] reported a 58-year-old Chinese man who had been diagnosed as having ALK Translocation-associated Renal Cell carcinoma in the upper pole of his right kidney. Radiology imaging of his abdomen, pelvis and renal tract including ultrasound scan and computed tomography scan revealed a $2.4 \mathrm{~cm} \times 2.2 \mathrm{~cm}$ hypoechoic mass that had clear cut margin within the upper pole of his right kidney by the ultrasound scan, and a $1.9 \mathrm{~cm} \times 1.8 \mathrm{~cm} \times 2.2 \mathrm{~cm}$ low-density mass within the upper pole of his right kidney. Ne metastasis was demonstrated. He 
did not have sickle cell trait, and he did not have any distinct clinical symptoms. He underwent laparoscopic right radical nephrectomy. Pathology examination of the tumour showed that the tumour comprised of sheets of large cells that contained abundant eosinophilic cytoplasm as well as indistinct cell borders that contained conspicuous intracytoplasmic vacuoles. Microscopy examination of the tumour showed that the nuclei of the tumour cells were enlarged and had features that were graded as nucleolar grade 4 . Immunohistochemistry staining of the tumour showed that the tumour cells had exhibited diffusely positive staining for: PAX8, Keratin (AE1/AE3), epithelial membrane antigen (EMA), as well as CK7. Fluorescent in situ hybridization (FISH) test of the tumour demonstrated re-arrangement of ALK within the tumour cells. Yang et al. [26] stated the following:

- The dramatic treatment benefit of therapies that target ALK for patients who have non-small cell carcinoma of the lung (NSCLC) that is driven by ALK fusion has now been widely accepted. [27] [28].

- Recently, the results of a few studies have demonstrated that ALK inhibitors, like ebtrectinib, and alectinib, could be dramatically effective with regard to the treatment of ALK Translocation-Associated Renal Cell Carcinomas [4] [29] [30]

- Despite the fact that the incidence rate of ALK TranslocationAssociated Renal Cell Carcinomas is low, the identification and in-depth investigation of ALK Translocation Renal Cell Carcinomas does seem to be very important in view of the potentially similar therapeutic response as well as prospects.

Yang et al. [26] made the ensuing concluding iterations:

- ALK-Translocation-Associated Renal Cell carcinoma is an uncommon sub-type of adult renal cell carcinoma.

- The diagnosis of ALK Translocation RCC is very difficult to diagnose in view of its very wide spectrum of histopathological features.

- $\quad$ They would suggest that renal cell carcinomas (RCCs) should be routinely screened for the expression of ALK by utilization of immunohistochemistry (IHC) staining studies due to the fact that the individual patient might benefit from ALK inhibitors therapy.

Jenneau et al. [31] reported an exceptional case of renal cell carcinoma (RCC) that was associated with ALK translocation in an adult. The tumour had been localized within the left kidney and had measured $4 \mathrm{~cm}$. Pathology examination of the tumour demonstrated that the tumour had comprised of sheets of large eosinophilic cells that contained frequently intra=cytoplasmic vacuoles. The nuclei were noted to be very large and were graded as nucleolar grade 3. Immunohistochemistry staining of the tumour showed that the tumour cells had exhibited diffusely positive staining for PAX8, and vimentin, as well as focally positive staining for CK7. Immunohistochemistry staining for ALK demonstrated diffusely positive staining and fluorescent in situ hybridization (FISH) test demonstrated re-arrangement of ALK in many tumour cells. Jeanneau et al. [31] stated the following:

- By the time of the report of their case, less than 17 cases of RCCs with ALK re-arrangements had been reported in children and adults.

- The prognosis of ALK Translocation-Associated RCC had remained uncertain; nevertheless, ALK re-arrangement could be of potential value for targeted treatment with crizotinib.

Hang et al. [32] reported a peculiar renal cell carcinoma which morphologically mimicked metanephric adenoma that harbored a novel PLEKHAF7-ALK fusion. Microscopy pathology examination of the tumour showed that the tumour had comprised of bland epithelial cells that contained scant to moderate amount of amphophilic cytoplasm, round and uniform nuclei, delicate chromatin, as well as inconspicuous nucleoli that were arranged in tightly packed small acini and angulated tubules. Microscopy examination of the tumour also demonstrated papillary formation, intraluminal glomeruloid tufts, microcysts, as well as solid nests. Psammomatous calcifications were visualized within the tumour. Immunohistochemistry studies of the tumour demonstrated that the tumour cells had exhibited diffusely positive staining for CK7, AMACR, PAX8, as well as ALK. But the tumour cells did exhibit negative staining for WT1< BRAF V600E, CD57, Carbonic anhydrase IX, TFE3, and cathepsin K. Fluorescence in situ hybridization (FISH) test of the tumour showed breaking apart of ALK. A novel PLEKHAF7 exon 18ALKexon20 fusion was identified with utilization of ArcherDX FusionPlex next-generation sequencing panel and this was additionally confirmed by means of reverse-transcriptase PCR. Hang et al. [32] made the ensuing conclusions:

- Their case had demonstrated that in contrast to previous reported cases that showed high-grade tumour cells, ALKRearranged renal cell carcinoma could manifest as low-grade renal tumour that simulate metanephric adenoma.

- Immunohistochemistry staining studies and molecular testing are helpful with regard to the identification of this tumour, which could be eligible for inhibitor-targeted treatment.

Tao et al. [5] reported a 22-year-old man who had manifested with visible haematuria and anaemia. He had computed tomography (CT) scan which showed a $14 \mathrm{~cm}$ x $13 \mathrm{~cm}$ x $12 \mathrm{~cm}$ heterogeneous mass which had almost completely replaced his right kidney parenchyma. He did undergo a right radical nephrectomy and pathology examination of the tumour showed a stage III (pT3aN1) high-grade (nuclear grade IV) renal cell carcinoma with pleomorphic features as well as 23 tumour positive lymph nodes. The tumour was felt to be completely resected. He had CT scan 2 months pursuant to his surgery which did not reveal any local recurrence or metastasis. Next-generation sequencing of the primary tumour demonstrated a VCL-ALK translocation generating a fusion between exon 16 of VCL and exon 20 of ALK. Histopathology examination of the tumour revealed markedly pleomorphic cells that contained abundant eosinophilic (rhabdoid) cytoplasm as well as cytoplasmic vacuoles. INI1 (BAF47) was retained by the tumour. Immunohistochemistry staining studies of the tumour showed overexpression of ALK. Fluorescence in situ hybridization (FISH) test confirmed VCL-ALK gene fusion. He had haemoglobin electrophoresis which confirmed presence of sickle cell trait. His 12-months post-operative surveillance radiology imaging showed presence of confluent lymph node enlargement within his right retro-crural space as well as an enlarged left superior mediastinal metastatic node which was biopsied and pathology examination of the specimen confirmed metastatic disease. The patient was enrolled in a clinical trial of entrectnib (RXDX-101); Clinical Trials.gov identifier: NCT02097810). Four weeks pursuant to commencement of entrectinib $600 \mathrm{mg}$ per day, he had a CT scan which showed $31.4 \%$ decrease in the size of the disease or partial response. The patient continued his treatment and at his 15 months follow-up radiology imaging had shown 61.9\% decrease in the size of the metastatic disease. His treatment with entrectinib was continued for 19 months which he tolerated well with the exception of grade 1 peripheral lower extremity oedema and grade 2 weight gain. After 19 months of treatment radiology follow-up imaging demonstrated progression of the metastatic disease with increased mediastinal lymph node enlargement and entrectinib treatment was stopped. Lessons that were learnt from this case report include (a) Patients who have ALK Translocation-associated Renal Cell Carcinomas might respond to entrectinib therapy. (b) Large sized ALK TranslocationAssociated Renal Cell Carcinomas that are also associated with lymph nodes positive for tumour would be aggressive tumours with a great chance of the subsequent development of metastases that would continue 
to progress and these metastatic lesions might initially respond to entrectinib therapy but would subsequently progress further. (c) Perhaps the best time to commence entrectinib therapy is immediately after complete excision of the tumour as adjuvant therapy so that if there are microscopic metastases that are too small for radiology imaging to identify the tumour cells would be completely destroy but if one waits till the metastatic tumour burden is large there could be problems in that perhaps the medicaments might not be able to completely destroy all the metastases. (b) Perhaps other additional adjuvant treatments including adjuvant radiotherapy and immunotherapy should also be tried in such situations of large sized tumours with nodal disease after the operation.

$\mathrm{Yu}$ et al. [10] embedded into tissue microarrays for immunohistochemistry staining a total of 477 Renal Cell Carcinoma (RCC) patients in China. They undertook fluorescence in situ hybridization (FISH) as well as fluorescence quantitative transcription polymerase chain reaction (RT-PCR) to identify as well as confirm rearrangement of ALK, as well as to identify the genes that are fused with ALK. They identified ALK expression in two out of 477 renal cell carcinomas ( $0.42 \%$ of cases). They undertook FISH analysis and two tumours showed either a $1 \mathrm{R} 1 \mathrm{G} 1 \mathrm{~F}$ or a $2 \mathrm{R} 2 \mathrm{G}$ signal pattern, which indicated re-arrangement that had involved ALK. They also undertook fluorescence quantitative RT-PCR which identified TPM3-ALK fusion and EML4-ALK fusion transcripts in two tumours respectively. They did analyse follow-up data on the two cases together with eight other ALKre-arranged Renal Cell Carcinomas (RCCs) that had been reported in the literature. They found that with regard to the outcome, two patients had died from renal cell carcinomas, during the $16^{\text {th }}$ month and $48^{\text {th }}$ month respectively pursuant to their surgery. The 5-year cancer-specific survival of the patients who had ALK-rearranged renal cell carcinomas (RCCs) were found to be lower in comparison with that of patients who had the International Society of Urological Pathology (ISUP) G1, G2, and G3 clear cell renal cell carcinoma (CCRCC) as well as papillary renal cell carcinoma (PRCC), but the 5-year cancer-specific survival was higher than that of patients who had G4 CCRCC and PRCC. Yu et al. [10] made the following conclusions:

- ALK-rearranged renal cell carcinoma (RCC) is an uncommon sub-type of renal cell carcinoma (RCC) which is associated with distinct histopathological features as well as poor prognosis.

- The identification of ALK-rearranged renal cell carcinoma (RCC) does have an important clinical significance in view of the fact that patients who have that type of carcinoma might derive benefit from ALK inhibitor treatment as is utilized in adenocarcinoma of the lung.

Smith et al. [8] reported the third case of a renal cell carcinoma that bore a fusion of the vinculin (VCL) as well as anaplastic kinase (ALK) genes. Smith et al. [8] stated that like the other two previously reported cases, their reported tumour did occur in a young six years old patient who had sickle cell trait which had demonstrated distinct morphology features that included medullary epicentre, dis-cohesive polygonal or spindled-shaped cells that contained prominent cytoplasmic vacuoles, as well as prominent lymphocytic infiltrate. The tumour cells did demonstrate focal membranous labelling for ALK protein with utilization of immunohistochemistry, ALK gene re-arrangement with utilization of fluorescence in situ hybridization, and a specific VCL-ALK gene fusion by utilization of reverse transcriptase polymerase reaction test. Smith et al. [8] stated that VCL-ALK renal cell carcinoma could represent the eighth $\left(8^{\text {th }}\right)$ sickle cell nephropathy.

Kusano et al. [20] stated that anaplastic lymphoma kinase (ALK) translocation renal cell carcinomas (ALK Translocation-associated RCCs) had been reported by many independent groups recently and that the clinical behaviour as well as the histopathological features of these carcinomas are not fully understood in view of the paucity of these cases. They described 2 cases of renal cell carcinomas that were associated with a novel striatin (STRN)-ALK fusion. The first case was that of a 33-yearold woman who had sickle cell trait who had undergone right nephrectomy for a right renal mass and who developed late recurrence within the para-aortic lymph nodes twice 10 years and 12 years pursuant to her initial surgery. Following her second recurrence, she was carefully observed without any treatment. Twenty six years pursuant to her initial nephrectomy, she underwent her second para-aortic lymphadenectomy as well as she underwent gastrectomy for a newly developed primary gastric cancer. The resected para-aortic lymph nodes were found upon pathology examination to have been largely replaced by metastatic carcinoma. The second case was that of a 38-year-old man who did not have sickle cell trait who had undergone cytoreductive nephrectomy that was followed by his treatment with sunitinib for metastatic renal cell carcinoma. Kusano et al. [20] stated that in both cases, the tumour upon pathology examination showed solid, papillary, tubular, as well as mucinous cribriform structures. Psammoma bodies were also occasionally visualized within the stroma. The tumour cells contained large nuclei and prominent nucleoli and the cells contained eosinophilic cytoplasm. Rhabdoid cells and signet-ring cells were also seen in the tumours. Intracytoplasmic deposition of mucin as well as background mucinous stroma were also visualized. With regard to the second case, tumour necrosis was visualized within some areas of the tumour. The tumour cells did exhibit diffusely positive staining for ALK with regard to both cases. By the utilization of fluorescence in situ hybridization test, ALK translocation was confirmed and further gene analysis was undertaken of the tumours which did reveal STRN-ALK fusion. Kusano et al. [20] iterated that these reported cases had provided great insight into ALK translocationassociated renal cell carcinomas.

Ahluwalia et al. [33] stated the following:

- Renal cell carcinoma with Xp11.2 translocations and TFE3 fusions (Xp11.2TRCC) had been recognized as a distinct tumour entity in 2004 World Health Organization (WHO) of kidney tumours [1]

- $\quad$ Renal cell carcinoma translocations which had been primarily described in the paediatric population and which had accounted for $30 \%$ of children had recently been reported in the adult population as associated with poorer prognosis [2].

The tumours had been typified by a variety of chromosome translocations, and all of the chromosome translocations have involved a breakpoint at Xp11.2 as well as fusion that involves the TFE gene (see figure 3). Ahluwalia et al. [33] reported two young female adult patients who had been referred to them. One of the patients was a 20-year-old, who was incidentally found to have a mass within the right kidney (who would be referred to as patient 1 in this summation), and the second patient was a 17-years, who had manifested with visible haematuria that was associated with blood clots as well as right flank pain (who would be referred to as patient 2). Contrast-enhanced computed tomography scan with regard to both patients demonstrated findings that were consistent with kidney tumour (see figure 4). Pursuant to the undertaking of appropriate assessment, both patients did undergo right radical nephrectomy. With regard to patient 1 , during the operation, the retroperitoneum was found to contain enlarged hilar lymph nodes. With regard to patient 1, macroscopic pathology examination of the nephrectomy specimen demonstrated a well-encapsulated predominantly unilocular cystic lesion that contained grey brown solid areas and focal areas of haemorrhage and the tumour measured $7.5 \mathrm{~cm} \mathrm{x} 9 \mathrm{~cm} \mathrm{x} 7 \mathrm{~cm}$ (see figure 5 a). With regard to patient 2, Macroscopic pathology examination of the specimen demonstrated a well-defined encapsulated grey white to yellow white solid/cystic lesion within the mid-pole of the right kidney that measured $3 \mathrm{~cm} \times 3 \mathrm{~cm} \times 5 \mathrm{~cm}$. Sinus fat infiltration by tumour was not visualized in any of the patients' tumours. Microscopic pathology 
examination of the tumour showed that the tumour had comprised of cells that had been arranged in papillary pattern and they had contained eosinophilic cytoplasm and prominent nucleoli. (see figure 5b). Psammoma bodies were frequently visualized in the tumour. Mitosis was occasionally visualized. The hilar lymph node upon microscopy examination was seen to contain neoplastic infiltration with regard to one of the patients (see figure 6). The differential diagnosis was between Renal Cell Carcinoma with Xp11 translocation and papillary Renal Cell Carcinoma type 2. Immunohistochemistry staining studies of the tumours showed that the tumour cells had exhibited positive staining for $\mathrm{Cd} 10$, Vimentin, and EMA but the tumour cells exhibited negative staining for CK7. The features of the tumours were adjudged to be suggestive of renal cell carcinoma with Xp11 translocation. TFE3 gene mutation study was further undertaken which demonstrated that the immunostaining had shown that the tumour cells were positively stained for TFE3 but negative for cathepsin K. FISH analysis of the tumours demonstrated that $55 \%$ and $36 \%$ of the cells had split TFE3 signal in patient 1 and patient 2 respectively, which did support the diagnosis of translocation renal cell carcinoma. At their follow-up assessments which was approximated 12 months following their operations, they were well with normal clinical examination findings, normal chest $\mathrm{x}$-ray, normal results of their laboratory blood tests and their MRI scans were normal with no evidence of any local recurrence or metastasis. Ahluwalia et al. [33] stated the following:

- Xp11.2 translocation renal cell carcinomas in adult patients could be associated with advanced stages, large tumour sizes, and extra-capsular disease and could manifest with metastatic disease with possible poor prognosis.

- Female preponderance tends to be seen in adults as was seen in their patients also.

- With regard to young patients, Xp11.2 renal cell carcinoma should be suspected if prominent lymph node metastases are present as was found in their patients.
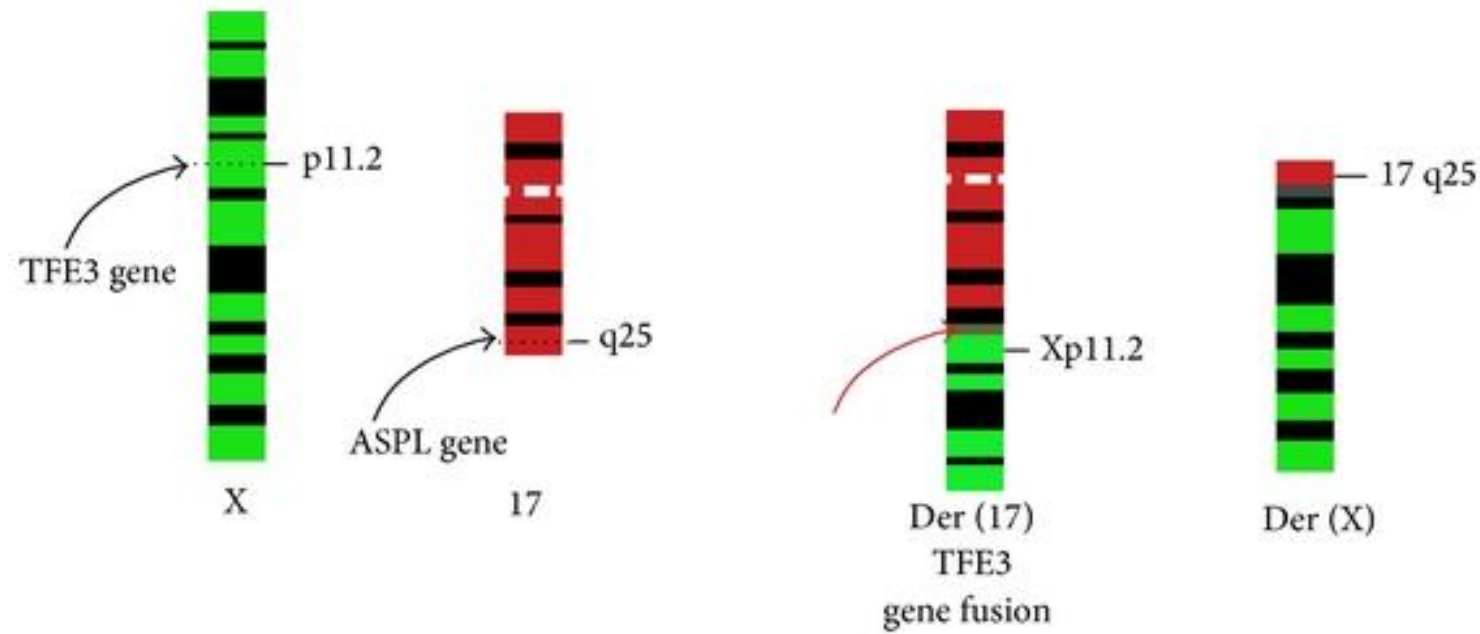

$\operatorname{Der}(\mathrm{X})$

gene fusion

Renal cell carcinoma associated with Xp11.2

translocation $46, \mathrm{X}, \mathrm{t}(\mathrm{X} ; 17)(\mathrm{p} 11.2 ; \mathrm{q} 25)$

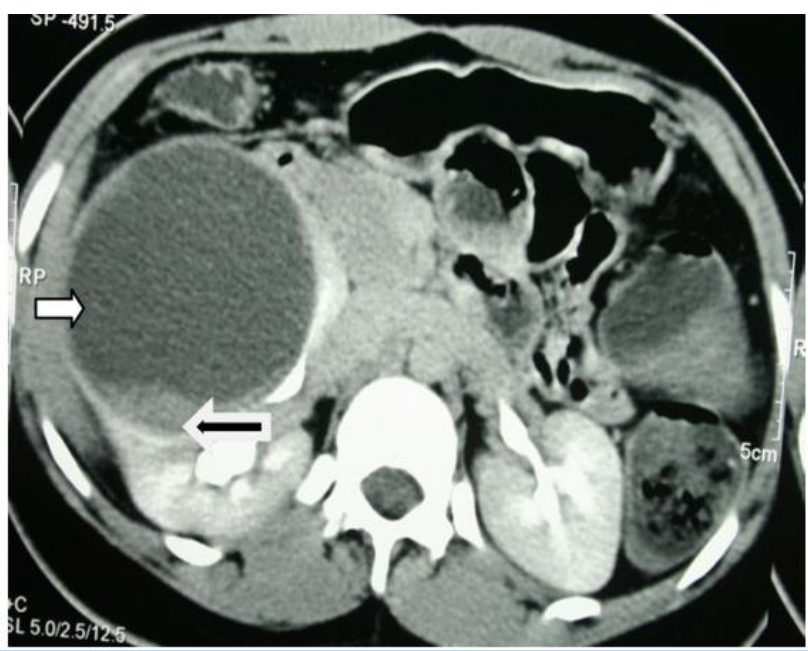

Figure 4

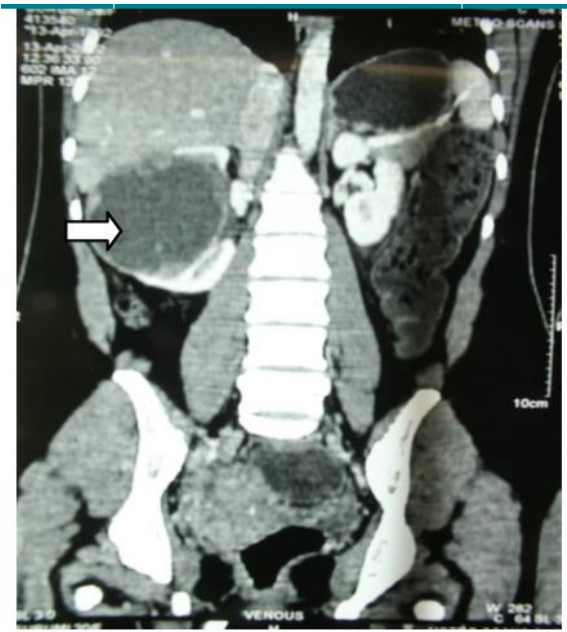

b 
Contrast CT scan of the abdomen and pelvis in patient 1 with (a) axial section and (b) coronal section showing a large predominantly cystic (white arrow) right renal mass measuring 9 × $8 \times 8 \mathrm{~cm}$ with solid mass (black arrow).[33].

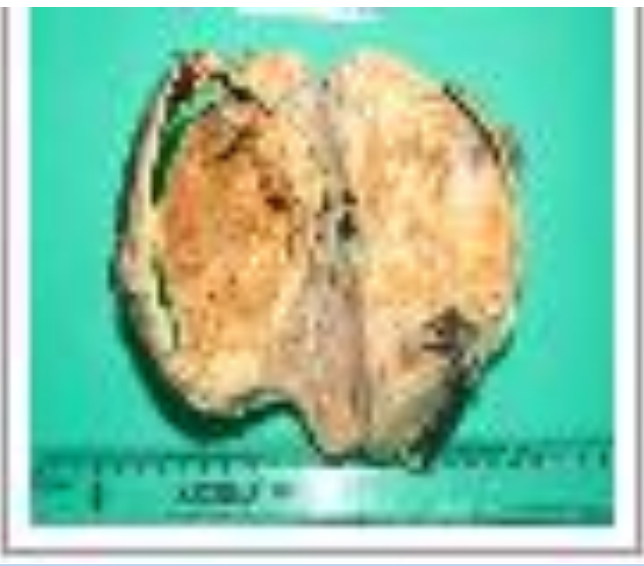

Figure 5.

(a)

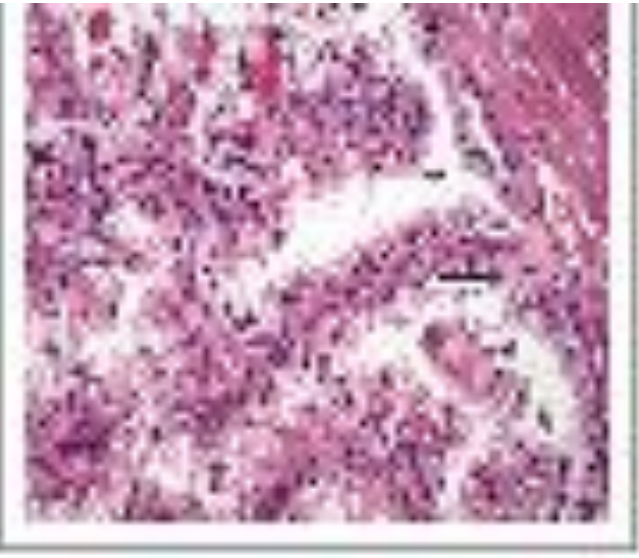

(b)
Cut surface showing well encapsulated predominantly unilocular cystic lesion with grey brown solid areas with focal areas of haemorrhage measuring $7.5 \times 9 \times 7 \mathrm{~cm}$ in size. (b) Microscopically, cells are arranged in papillary pattern (arrow) with some areas showing alveolar and nesting pattern. Cells showed abundant clear to eosinophilic cytoplasm with prominent nucleoli [33].

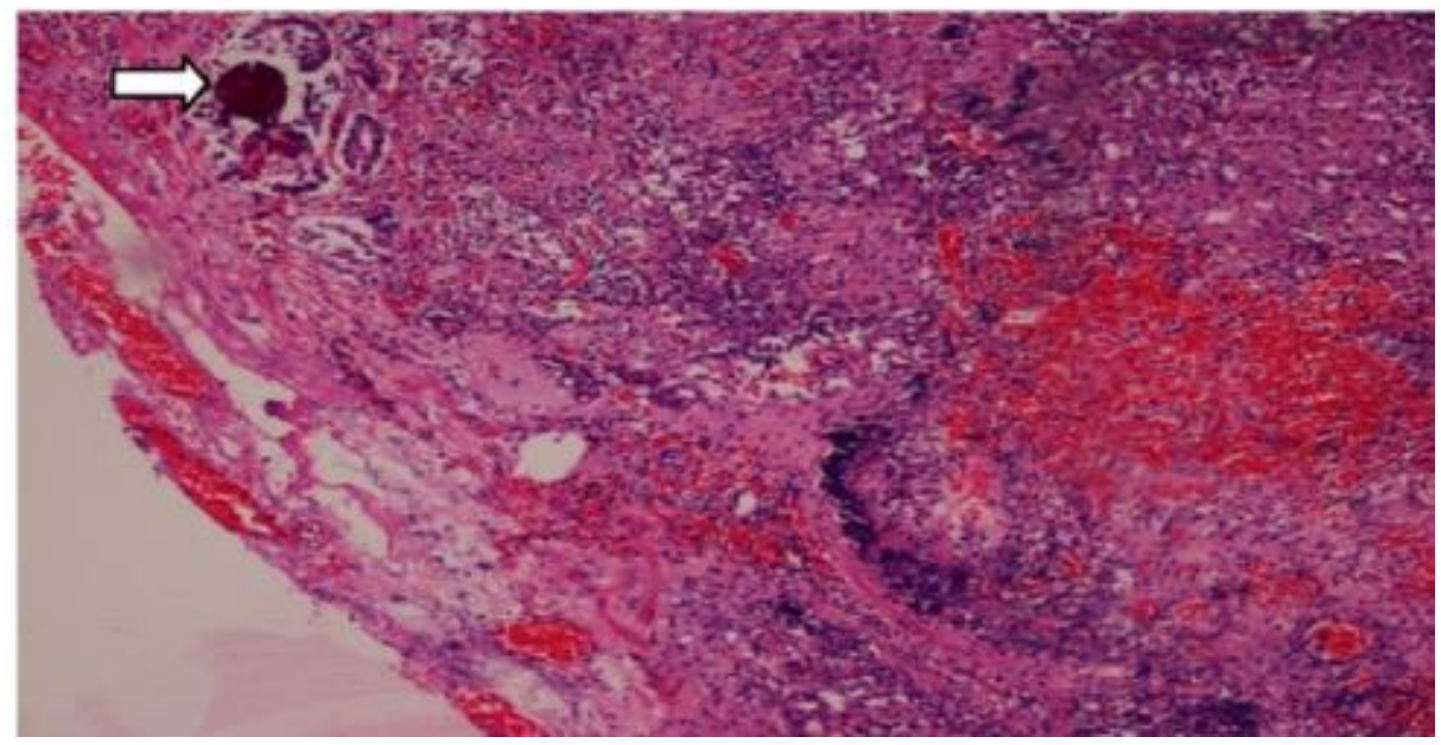

Figure 6.Hilar lymph node showing neoplastic infiltrate along with psammoma bodies (arrow).

undertook a study which was aimed at determining the incidence of Xp11 translocation renal cell carcinoma (RCC) in adults patients by utilization of cytogenetics and immunohistochemistry studies. Komai et al. [34] undertook cytogenetic studies prospectively with the use of tumour samples obtained from 443 consecutive adult Japanese patients whose ages had ranged between 15 years and 89 years who had undergone nephrectomy for renal cell carcinoma. They undertook TFE3 immunohistochemistry studies for cases in which cytogenetic results had not been obtained. They examined the clinicopathological characteristics of Xp11 translocation renal cell carcinoma. Komai et al. [34] stated that mitotic cells that were suitable for cytogenetic analysis had been obtained in 244 tumour samples that amounted to $55 \%$ of all the tumours, and among these, they did identify 4 cases of Xp11 translocation renal cell carcinoma that amounted to $1.6 \%$ of the tumours. Through the undertaking of TFE3 immunohistochemistry studies, 3 postive cases that amounted to $1.5 \%$ the tumours among 199 cases were obtained. The ages of the 7 patients had ranged between 15 years and 59 years and their median age was 41 years, and $15 \%$ of the renal carcinoma patients that accounted for 4 patients out of the 26 individuals who were younger than 45 years of age had this type of renal cell carcinoma. Out of the four (4) Xp11 translocation renal cell carcinoma patients whose karyotypes had been determined, two had an ASPL-TFE3 gene fusion. Out of these two (2) patients, one (1) patient had lung metastasis at initial presentation and the other patient developed hepatic metastasis 12 months pursuant to undergoing nephrectomy and died of the disease. The remaining two patients did have PRCC-TFE3 and PSF-TFE3 gene fusions respectively. Both of the patients did have nodal involvement but they remained free of disease for 3 and 5 years, respectively, following urgical resection of their lymph node metastases. Out of the 3 individuals who had been diagnosed with utilization of immunohistochemistry staining studies, 1 had nodal metastases and died 9 months pursuant to undergoing surgery. Komai et al. [34] made the ensuing conclusions: 
- Their reported study, was the first study to determine the incidence of Xp11 translocation renal cell carcinoma in adult patients.

- They had found that the disease is relatively common in young adults.

\section{Conclusions}

- ALK Translocation-Associated Renal Cell Carcinoma is an uncommon carcinoma that tends to be sporadically reported in children with sickle cell trait, and adults who do not have sickle cell trait.

- ALK Translocation-Associated Renal Cell Carcinoma may be diagnosed incidentally or following investigations of symptoms that are similar to symptoms of common renal neoplasms.

- Diagnosis of ALK-Translocation-Associated Renal Cell Carcinoma tends to be based upon a combination of various morphological features in combination with immunohistochemistry staining features, electron microscopy features as well as cytogenetics features that specific for the disease.

- ALK-Translocation Renal Cell Carcinoma has mainly been treated by means of complete excision of a localized tumour / locally advanced tumours by means of partial nephrectomy / nephrectomy and metastatic tumours have shown response to utilization of ALK inhibitors.

- Good short-, and medium-term outcome have been reported but long term outcome data has not been provided in majority of previously reported cases; nevertheless, cases of metastatic disease at initial presentation as well as subsequent reports of metastasis after nephrectomy and death have been reported.

- If routine radiology imaging sceening of sickle cell trait patients are undertaken, ALK Trasnlocation-Associated Renal Cell Carcinomas could be diagnosed early.

- The options of treatment for localized / locally advanced ALKTranslocationAssociated Renal Cell Carcinomas should be expanded to include: (a) Partial nephrectomy, (b) radical nephrectomy plus lymph node dissection, (c) cryotherapy, (d) radiofrequency ablation, (e ) irreversible electroporation, plus / minus adjuvant therapy by means of (a) chemotherapy, (b) radiotherapy, (c) ALK inhibitors, (d) Immunotherapy.

- Considering that large-sized and locally advanced ALK Translocation-Associated Renal Cell Carcinomas would tend to subsequently develop local recurrence and metastasis in the short term or after a long term, their treatment of curative intent should include complete excision of tumour by nephrectomy plus lymph node dissection plus adjuvant therapy with ALK inhibitor plus chemotherapy and / or radiotherapy plus or immunotherapy.

- A global multi-centre trial of various treatment options for ALK Translocation-Associated Renal Cell Carcinomas should be undertaken with long-term follow-up following diagnosis established based upon routine radiology-imaging guided biopsies of all kidney lesions that are suspicious for malignancy.

\section{Conflict of interest - None}

\section{Acknowledgements}

\section{Acknowledgements to:}

- Yonsei Medical Journal and Yonsei University College of Medicine for granting permission for reproduction of figures and contents of their journal articles under copyright $(\subset$ Yonsei University College of Medicine. This is an Open Access article distributed under the terms of the Creative Commons Attribution Non-Commercial License (https://creativecommons.org/licenses/by-nc/4.0/) which permits unrestricted non-commercial use, distribution and reproduction in any medium, provided the original work is properly cited.

- $\quad$ Case Reports in Urology and Hindawi Publishing Limited for granting permission for reproduction of figures and contents of their journal articles under Copyright (C) 2013 Puneet Ahluwalia et al. This is an open access article distributed under the Creative Commons Attribution License, which permits unrestricted use, distribution, and reproduction in any medium, provided the original work is properly cited.

\section{References}

1. Pulford K, Lamant L, Morris SW, Butler LH, Wood KM, Stroud D, Delsol G, Mason D Y. (1997) Detection of anaplastic lymphoma kinase (ALK) and nucleolar protein nucleophosmin (NPM)-ALK proteins in normal and neoplastic cells with the monoclonal antibody ALK1. Blood. 89:1394-1404.

2. Hallberg B, Palmer RH. (2013) Mechanistic insight into ALK receptor tyrosine kinase in human cancer biology. Nat Rev Cancer.; 13:685-700.

3. Woo C G, Yun S J, Son S-M, Lim Y N, Lee O-J. (2020) Characteristics of Renal Cell Carcinoma Haboring TPM3-ALK Fusion. Yonsei Medical Journal. 61(3): 262 - 266.

4. Pal S K, Bergerot P, Dizman N, Bergerot C, Adashek J, Madison R, Chung J H, Ali S M, Jones J O, Salgia R. (2018) Responses to alectinib in ALK-rearranged papillary renal cell carcinoma. Eur Urol. Jul; 74(1):124 - 128.

5. Tao J J, Wei G, Patel R, Fagan P, Hao X, Bridge J A, Arcila M A, Al-Ahmadie H, Lee C H, Li G, Drilon A. (2018) ALK fusions in renal cell carcinoma: response to entrectinib. JCO Precis Oncol.

6. Bodokh Y, Ambrosetti D, Kubiniek V, Tibi B, Durand M, Amiel J, Pertuit M, Barlier A, Pedeutour F. (2018) ALK-TPM3 rearrangement in adult renal cell carcinoma: report of a new case showing loss of chromosome 3 and literature review. Cancer Genet.221: 31-37.

7. Thorner PS, Shago M, Marrano P, Shaikh F, Somers GR. (2016) TFE3-positive renal cell carcinomas are not always Xp11 translocation carcinomas: report of a case with a TPM3ALK translocation. Pathol Res Pract. 212:937-942.

8. Smith N E, Deyrup A T, Mariño-Enriquez A, Fletcher J A, Bridge J A, Illei P B, et al. (2014) VCL-ALK renal cell carcinoma in children with sickle-cell trait: the eighth sicklecell nephropathy? Am J Surg Pathol.38 (6):858-863.

9. Cajaiba MM, Dyer LM, Geller JI, Jennings LJ, George D, Kirschmann D, Rohan S M, Cost N G, Khanna G, Mullen E A, Dome J S, Fernandez C V, Perlman E J. (2018) The classification of pediatric and young adult renal cell carcinomas registered on the children's oncology group (COG) protocol AREN03B2 after focused genetic testing. Cancer. 124(16):3381-3389.

10. Yu W, Wang Y, Jiang Y, Zhang W, Li Y. (2017) Genetic analysis and clinicopathological features of ALK-rearranged renal cell carcinoma in a large series of resected Chinese renal cell carcinoma patients and literature review. Histopathology. 71(1):53-62.

11. Tretiakova M, Zynger D. (2019) Kidney tumor Adult renal cell carcinoma - rare ALK translocation. Topic completed Dec 17. 
12. Kuroda N, Sugawara E, Kusano H, Yuba Y, Yorita K, Takeuchi K. (2018) A review of ALK-rearranged renal cell carcinomas with a focus on clinical and pathobiological aspects. Pol J Pathol.69 (2):109-113.

13. Trpkov K, Hes O. (2019) New and emerging renal entities: a perspective post-WHO 2016 classification. Histopathology. 74(1):31-59.

14. Debelenko LV, Raimondi SC, Daw N, Shrivakumar B R, Huang D, Nelson M, Bridge J A. (2011) Renal cell carcinoma with novel VCL-ALK fusion: new representative of ALKassociated tumor spectrum. Mod Pathol.24 (3):430-442.

15. Sugawara E, Togashi Y, Kuroda N, Sakata S, Hatano S, Asaka R, Yuasa T, Yonese J, Kitagawa M, Mano H, Ishikawa Y, Takeuchi K. (2012) Identification of anaplastic lymphoma kinase fusions in renal cancer: large-scale immunohistochemical screening by the intercalated antibodyenhanced polymer method. Cancer.118 (18):4427-4436.

16. Pal S K, Bergerot P, Dizman N, Bergerot C, Adashek J, Madison R, Chung J H, Ali S M, Jones J O, SAlgia R. (2018) Responses to Alectinib in ALK-rearranged Papillary Renal Cell Carcinoma. Eur Urol.74 (1):124-128.

17. Delahunt B, Srigley JR. (2015) The evolving classification of renal cell neoplasia. Semin Diagn Pathol. 32(2):90-102.

18. Cajaiba M M, Jennings L J, Rohan S M, Perez-Atayde J R, Marino-Enriquez A, Fletcher J A, Geller J I, Leuer L M C, Bridge J A, Perlman E J. (2016) ALK-rearranged renal cell carcinomas in children. Genes Chromosomes Cancer. 55(5):442-451.

19. Mariño-Enríquez A, Ou WB, Weldon CB, Fletcher JA, PérezAtayde AR. (2011) ALK rearrangement in sickle cell traitassociated renal medullary carcinoma. Genes Chromosomes Cancer.50 (3):146-153.

20. Kusano H, Togashi Y, Akiba J, Moriya F, Baba K, Matsuzaki N, Yuba Y, Shiraishi Y, Kanamaru H, Kuroda N, Sakata S, Takeuchi K, Yano H. (2016) Two Cases of Renal Cell Carcinoma Harboring a Novel STRN-ALK Fusion Gene. Am J Surg Pathol.40 (6):761-769.

21. Ryan C, Mayer N, Cunningham J, Hislop G, Pratt N, Fleming S. (2014) Increased ALK1 copy number and renal cell carcinoma-a case report. Virchows Arch.464 (2):241-245.

22. Sukov WR, Hodge JC, Lohse CM, et al. (2012) ALK alterations in adult renal cell carcinoma: frequency, clinicopathologic features and outcome in a large series of consecutively treated patients. Mod Pathol.25 (11):1516-1525.

23. Lee C, Park J W, Suh J H, Nam K H, Moon K C. (2013) ALKPositive Renal Cell Carcinoma in a Large Series of Consecutively Resected Korean Renal Cell Carcinoma Patients. The Korean Journal of Pathology. Oct; 47(5): 452 457.
24. Chen W, Li W, Bai B, Wei H. (2020) Identification of anaplastic lymphoma kinase fusions in clear cell renal cell carcinoma. Oncology Letters.43 (3): 817-826.

25. Kuroda N, Trpkov K, Gao Y, Tretiakova M, Liu Y J, Ulamec M, Takeuchi K, Agaimy A, Przybycin C, Magi-Galluzzi C, Fushimi S, Kojima F, Sibony M, Hang J F, Pan C C, Yilmaz A, Siadat F, Sugawara E, Just P A, Ptakova N, Hes O. (2020) ALK rearranged renal cell carcinoma (ALK-RCC): a multiinstitutional study of twelve cases with identification of novel partner genes CLIP1, KIF5B and KIAA1217. Mod Pathol.

26. Yang J, Dong L, Du H, Li X B, Liang Y X, Liu G R. (2019) ALK-TPM3 rearrangement in adult renal cell carcinoma: a case report and literature review. Diagn Pathol, 14, 112.

27. Shaw AT, Kim DW, Mehra R, et al. (2014) Ceritinib in ALKrearranged non-small-cell lung cancer. $\mathrm{N}$ Engl $\mathrm{J}$ Med.370:1189-1197.

28. Ou S H, Ahn J S, De Petris L, et al. (2016) Alectinib in crizotinib-refractory ALK-rearranged non-small-cell lung cancer: a phase II global study. J Clin Oncol.34: 661- 668.

29. Ross JS, Ali S, Fasan O, et al. (2017) ALK fusions in a wide variety of tumor types respond to anti-ALK targeted therapy. Oncologist.22:1444-1450.

30. Jessica Roopal Patel et al. (2018) ALK fusions in renal cell carcinoma: response to entrectinib. JCO Precision Oncology.2:1-8.

31. Jenneau M, Gregoire V, Desplechain C, Escande F, Tica D P, Aubert S, Leroy X. (2016) ALK rearrangements-associated renal cell carcinoma (RCC) with unique pathological features in an adult. Pathology - Research and Practice. 212(11): 10641066.

32. Hang J F, Pan C C, Chung H J. (2020) ALK-rearranged renal cell carcinoma with a novel PLEKHAF7-ALK translocation and metanephric adenoma-like morphology. Archiv für Pathologische Anatomie und Physiologie und für Klinissche Medicine 463(3).

33. Ahluwalia P, Nair B, Kumar G. (2013) Renal Cell Carcinoma Associated with Xp11.2 Translocation/TFE3 Gene Fusion: A Rare Case Report with Review of the Literature. Case Reports in Urology.

34. Komai Y, Fujiwara M, Fujii Y, Mukai H, Yonese J, Kawakami S, Yamamoto S, Migita T, Ishikawa Y, Kurata M, Nakamura T, Fukui I. (2009) Adult Xp11 Translocation Renal Cell Carcinoma Diagnosed by Cytogenetics and Immunohistochemistry. Clinical Cancer Research. 15(4): 1170-1176. 